\title{
A First-Principles Study of Gas Molecule Adsorption on Carbon-, Nitrogen-, and Oxygen-Doped Two-Dimensional Borophene
}

\author{
Xinmao Qin $\mathbb{D}^{\mathrm{D}}$, Wanjun Yan $\mathbb{D}$, Dongxiang Li, Zhongzheng Zhang $\mathbb{D}$, and Shaobo Chen $\mathbb{1}$ \\ School of Electronic and Information Engineering, Anshun University, Anshun 561000, China \\ Correspondence should be addressed to Wanjun Yan; yanwanjun7817@163.com
}

Received 25 August 2021; Revised 22 November 2021; Accepted 2 December 2021; Published 20 December 2021

Academic Editor: Maheswar Nayak

Copyright (C) 2021 Xinmao Qin et al. This is an open access article distributed under the Creative Commons Attribution License, which permits unrestricted use, distribution, and reproduction in any medium, provided the original work is properly cited.

\begin{abstract}
A first-principles study was performed to investigate the adsorption properties of gas molecules $\left(\mathrm{CO}, \mathrm{CO}_{2}, \mathrm{NO}\right.$, and $\left.\mathrm{NO}_{2}\right)$ on carbon- (C-), nitrogen- (N-), and oxygen-doped (O) borophene. The adsorption energies, adsorption configurations, Mulliken charge population, surface work functions, and density of states (DOS) of the most stable doped borophene/gas-molecule configurations were calculated, and the interaction mechanisms between the gas molecules and the doped borophene were further analyzed. The results indicated that most of the gas molecules exhibited strong chemisorption at the VB site (the center of valley bottom B-B bond) of the doped borophene (compared to pristine borophene). Electronic property analysis of the C-doped borophene/ $\mathrm{CO}_{2}$ and the $\mathrm{NO}_{2}$ adsorption system revealed that there were numerous charge transfers from the C-doped borophene to the $\mathrm{CO}_{2}$ and $\mathrm{NO}_{2}$ molecules. This indicated that $\mathrm{C}$-doped borophene was an electron donor, and the $\mathrm{CO}_{2}$ and $\mathrm{NO}_{2}$ molecules served as electron acceptors. In contrast to variations in the adsorption energies, electronic properties, and surface work functions of the different gas, C-, N-, and O-doped borophene adsorption systems, we concluded that the C-, N-, and O-doped borophene materials will improve the sensitivity of $\mathrm{CO}, \mathrm{CO}_{2}$, and $\mathrm{NO}_{2}$ molecule; this improvement of adsorption properties indicated that $\mathrm{C}-, \mathrm{N}-$, and $\mathrm{O}$-doped borophene materials are excellent candidates for surface work functions transistor to detect gas molecules.
\end{abstract}

\section{Introduction}

Graphene is a new two-dimensional nanomaterial that was first prepared in 2004 by Novoselov et al. [1] using mechanical exfoliation. Since then, the structures, properties, and applications of new two-dimensional monolayer materials have become some of the most interesting areas of study. Borophene, a new type of two-dimensional singleatom layer nanomaterial, has been successfully synthesized on single crystal silver (crystallographic plane of (111)) substrates under ultrahigh-vacuum conditions [2]. Its unique geometrical and electronic structure endows borophene with excellent physical, chemical, and mechanical properties, such as high thermal conductivity $[3,4]$, anisotropic electronic [5] and optical properties [6], superconducting properties [7], and ultrahigh mechanical modulus [8]. These properties make borophene suitable for various applications, such as alkali metal ion batteries $[9,10]$, hydrogen storage [11, 12], supercapacitors [13], and gas molecule sensors [14-17]. In addition, harmful gases such as
$\mathrm{CO}, \mathrm{NO}, \mathrm{NO}_{2}, \mathrm{NH}_{3}, \mathrm{SO}_{2}$, and $\mathrm{HCOH}$ cause environmental pollution, which is becoming increasingly serious. Thus, studies on the adsorption and detection of harmful gases are important, and the development of new harmful gas sensors with high sensitivity and fast response is gaining significant attention. Studies have shown that 2-Pmmn two-dimensional borophene possesses an extraordinary wrinkled geometry [2], excellent surface-to-volume ratio, and anisotropic electronic properties, suggesting that the charge states and work functions of borophene could be easily modified by gas molecule adsorption, allowing it to be used in sensors and gas detection. Numerous studies have reported the first-principles calculations, for the adsorption of borophene for gas molecules. Liu et al. [14] calculated the adsorption configurations, adsorption energies, and electronic properties of gas molecules absorbed on borophene and found that $\mathrm{CO}, \mathrm{CO}_{2}, \mathrm{NH}_{3}, \mathrm{NO}$, and $\mathrm{NO}_{2}$ were chemisorbed on borophene, while $\mathrm{CH}_{4}$ physisorbed on borophene. Their results revealed that borophene could be used as a highly sensitive $\mathrm{CO}$ and $\mathrm{CO}_{2}$ gas sensor. Cui [16] 
used the density functional theory (DFT) method to study the adsorption behavior of borophene for $\mathrm{SO}_{2}$ molecules and showed that borophene had good adsorption capacity toward $\mathrm{SO}_{2}$ molecules by chemisorption. The calculations also indicated meaningful applications of the materials as $\mathrm{SO}_{2}$ adsorbents in the near future. Tan et al. [17] examined the possibility of conductive borophene nanosheets as promising sorbent materials for charge-modulated switchable $\mathrm{CO}_{2}$ capture, and the results indicated that the binding strength of $\mathrm{CO}_{2}$ molecules on negatively charged borophene could be significantly enhanced by injecting extra electrons into the adsorbent. Nagarajan and Chandiramouli [15] also calculated the electronic and ethanol adsorption properties of a hydrogenated 2D-borophene nanosheet device using nonequilibrium Green's function (NEGF) and DFT methods. Their results also confirmed that borophene nanosheets could be used as ethanol detectors. Furthermore, the adsorption energy, adsorption sites, and charge transfer of $\mathrm{CO}$ and $\mathrm{NO}$ on borophene were analyzed at the atomistic level [18], and their finding showed that borophene could be used for the development of chemical nanosensors to detect CO and NO molecules. Shen et al. [19] first designed a borophene/ $\mathrm{MoS}_{2}$ heterostructure and investigated the adsorption behavior of small gas molecules (CO, $\mathrm{CO}_{2}, \mathrm{NO}, \mathrm{NO}_{2}$, and $\mathrm{NH}_{3}$ ) on borophene surfaces, and their results showed that, except for $\mathrm{CO}_{2}$, the other four molecules adsorbed on borophene through chemisorption. However, all of the above studies focused on the calculations of pristine borophene on gas molecules. The edge functionalization, the nonedge defects, and chemical decorations of the twodimensional materials can provide additional modes of functionalization to tailor the electronic, chemical, optical, and magnetic properties of materials. The modified borophene materials and devices with excellent adsorption properties are still expected for next-generation gas molecules sensors, with the inadvertent introduction of various topological defects (vacancies, substitutional atoms, or adatoms) and other large defects (nanopores and nanoholes), which were unavoidable during the preparation and manipulation of borophene based devices. Previous studies have shown that structural defects in borophene sheets greatly affected their properties [20, 21]. For example, using DFT calculations, Li et al. [12], Chen et al. [22], and Wang et al. [23] found that $\mathrm{Li}_{-}, \mathrm{Na}-, \mathrm{Ca}-$, and $\mathrm{K}$-decorated borophene could be a promising $\mathrm{H}_{2}$ storage material for $\mathrm{H}_{2}$ fuel battery. In addition, Kumar [24] explored the structural parameters and gas adsorption properties of $\mathrm{CO}, \mathrm{NO}, \mathrm{CO}_{2}, \mathrm{NO}_{2}$, and $\mathrm{NH}_{3}$ gas molecules adsorbed over transition metal atom embedded borophene sheets and found that gas adsorption could be enhanced by embedding transition metal atoms into borophene sheets. Furthermore, the effects of sodium-decorated borophene on the adsorption of $\mathrm{CO}$ and $\mathrm{CO}_{2}$ molecules were determined [25], and they found that Na-decorated borophene monolayers could be used as sensors to detect $\mathrm{CO}$ and $\mathrm{CO}_{2}$ molecules in the atmosphere. Therefore, it is important to investigate the effects of dopants on the gas molecule adsorption properties of borophene sheets.

In this work, we used first-principles calculations based on DFT to study the adsorption behavior of $\mathrm{CO}, \mathrm{CO}_{2}, \mathrm{NO}$, and $\mathrm{NO}_{2}$ small gas molecules on $\mathrm{C}-, \mathrm{N}-$, and $\mathrm{O}$-doped borophene sheets. By analyzing the adsorption energy, adsorption configuration, Mulliken charge population, work functions, and density of states (DOS) of gas molecules on doped borophene, we concluded that the C-, N-, and $\mathrm{O}$-doped borophene materials may be excellent candidates for gas detection applications.

\section{Methods and Calculations}

All calculations were performed using the Cambridge Sequential Total Energy Package (CASTEP) based on the DFT [26]. In these calculations, the Perdew-Burke-Ernzerhof (PBE) function of generalized gradient approximation (GGA) was used to assess the exchange correlation energy between the electrons [27], and the ultrasoft pseudopotential was used to describe the interactions between the ion core and electrons [28]. Structural optimization and energy calculations were carried out using a plane wave basis set to a cut-off energy of $400 \mathrm{eV}$ and a $4 \times 4 \times 1$ $\mathrm{k}$-point mesh in the Brillouin zone. The configurations for the gas molecule-borophene systems were optimized by fully relaxing the atomic structures until the remaining forces were smaller than $0.03 \mathrm{eV} / \AA$. Energy convergence was $10^{-5} \mathrm{eV} /$ atom between the two steps, and a vacuum of $20 \AA$ was employed along the Z-direction of the doped borophene sheets to eliminate interactions between the borophene sheets.

The 2-Pmmn borophene model is shown in Figure 1. The $4 \times 3$ supercell borophene model consisted of 24 boron atoms, and the optimal lattice parameters were $a=6.5032 \AA$, $b=8.70487 \AA$, and $c=20 \AA$. In the model, $\mathrm{T}, \mathrm{TB}, \mathrm{V}$, and $\mathrm{VB}$ denoted the top site of the boron atom, the top-bridge site (the center of top B-B bond), the valley bottom of the boron atom, and the valley bottom-bridge site (the center of the valley bottom B-B bond), respectively (Figure 1). The C-, N-, and $\mathrm{O}$-doped atoms were substituted at the T-site or V-site with the boron atom in borophene. The small gas molecules were then positioned vertically in the four highly symmetrical adsorption sites of doped borophene, and the best adsorption sites and adsorption energies were obtained after structural optimization. The adsorption energy of the small gas molecules on $\mathrm{C}_{-}, \mathrm{N}_{-}$, and $\mathrm{O}$-doped borophene was defined by

$$
E_{a d}=E_{\text {molecule/doped-borophene }}-E_{\text {doped-borophene }}-E_{\text {molecule }} \text {, }
$$

where $E_{\text {molecule/doped-borophene, }} E_{\text {doped-borophene, and }} E_{\text {molecule }}$ are the total energy of the optimized adsorption configuration of the small molecule on the doped borophene system, the total energy of the doped borophene sheet, and the total energy of the isolated small gas molecule, respectively. In the calculations of adsorption energies, the zero-point energy (ZPE) contributions were neglected, owing to Gholizadeh and $\mathrm{Yu}$ [29] who found that the zero-point energy (ZPE) contributions can be omitted in most cases. To calculate the DOS, the $\mathrm{k}$-point was set to $15 \times 15 \times 1$ for accuracy.

\section{Results and Discussion}

3.1. Geometries and Electronic Properties of $C$-, $N$-, and $\mathrm{O}$-Doped Borophene. The C-doped, N-doped, and O-doped borophene were obtained by substituting a boron atom. The 


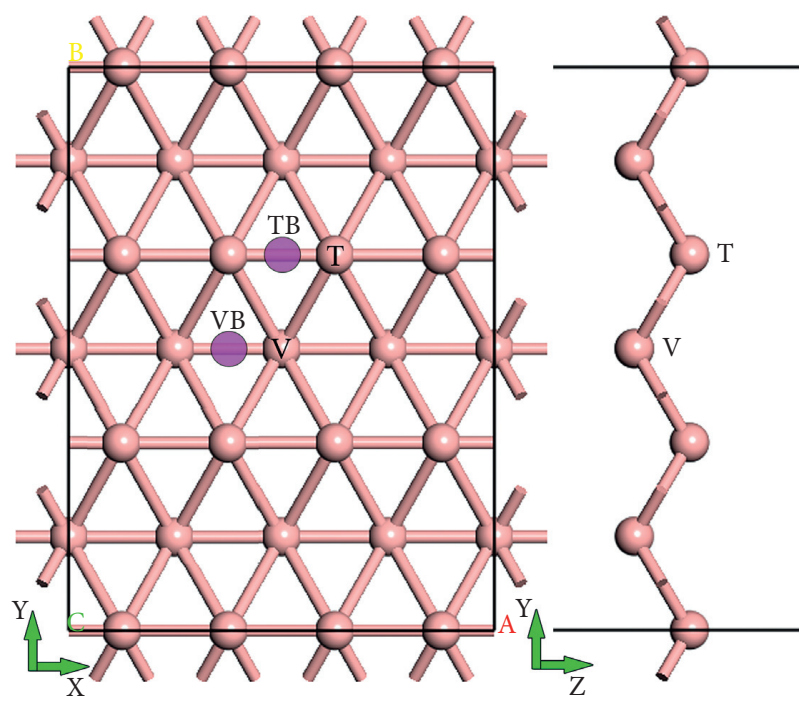

Figure 1: The crystal structure of the 2-Pmmn borophene, showing the top and side views, and the adsorption sites of the gas molecule on borophene.

fully relaxed geometric structures of pristine borophene, C-doped, N-doped, and O-doped borophene are shown in Figure 2. And the bond length, bond populations, and atomic populations are shown in Table 1. From Figure 2(a) and Table 1, for the pristine borophene sheet, the bond length of B20-B21 and B21-B22 bond is $1.880 \AA$ and $1.626 \AA$, respectively (consistent with the results of $1.879 \AA$ and $1.613 \AA$ from Peng [6]). The bond population of both B20$\mathrm{B} 21$ and B21-B22 bond is 0.20 , and the charge populations of boron atom are $0.0 \mathrm{e}$. After the carbon atom, nitrogen atom, and oxygen atom substituting the boron atom, the perfect geometric structures of borophene were disturbed (the top view and side view of Figures 2(b)-2(d)). The C-doped borophene lead to the B20-C bond (length of $1.541 \AA$ ) and B23-C bond (length of $1.538 \AA$ ) formation, and our calculated $\mathrm{C}-\mathrm{B}$ bond length of borophene sheet is in accord with Gholizadeh's reports [30] of B-C bond length of $1.493 \AA$ for boron atom-doped graphene sheet. The bond populations of both $\mathrm{B} 20-\mathrm{C}$ bond and $\mathrm{B} 23-\mathrm{C}$ bond are 1.16, which are much larger than the bond populations $(0.20)$ of B-B bonds for pristine borophene. From the point of view of the atomic charge populations, it is can be seen that the carbon atom gains $0.3 \mathrm{e}$, of which $0.26 \mathrm{e}$ was contributed by the two boron atoms (both B20 and B23 lost $0.13 \mathrm{e}$ ). The nitrogen atom doping the borophene results in the geometric structures of perfect borophene sheet extensive distortion (Figure 2(c)). The nitrogen atom and their nearest three boron atoms (B20, B21, and B23) form a triangular pyramid structure. And the bond populations of B20-N (bond length of $1.499 \AA$ ), B21-N $(1.500 \AA)$, and $\mathrm{B} 23-\mathrm{N}(1.500 \AA)$ are $0.91,0.58$, and 0.76 , respectively. The nitrogen atom obtains $0.6 \mathrm{e}$ from the nearest three boron atoms (B20, B21, and B23). When the oxygen atom is doping borophene, the B20, O, and B23 atoms form a B-O-B triangular structure, and a six-membered ring vacancy defect is left in the borophene sheet. The bond populations of B20-O (1.412 $\AA$ ) and B23-O (1.507 $\AA$ ) are 0.71 and 0.53 , respectively. The oxygen atom obtains 0.62 e from the nearest two boron atoms (B20 and B23). Based on the analysis of the geometric structures and charge populations of C-doped, $\mathrm{N}$-doped, and O-doped borophene, we can conclude that the doped heteroatoms (carbon nitrogen and oxygen) interact strongly with the boron atoms of borophene by a large amount of charge transfer from boron atoms to doped heteroatom.

3.2. Analysis of Doped Borophene Adsorption. The adsorption energy variations of the $\mathrm{CO}, \mathrm{CO}_{2}, \mathrm{NO}$, and $\mathrm{NO}_{2}$ molecules on $\mathrm{C}-, \mathrm{N}-$, and $\mathrm{O}$-doped borophene at different adsorption sites are shown in Figure 3, and the optimized adsorption structures are shown in Figure 4.

For most adsorption configurations, with variations in adsorption site from the T-site, TB-site, $\mathrm{V}$-site, to the VBsite, the adsorption energies of $\mathrm{CO}, \mathrm{CO}_{2}, \mathrm{NO}$, and $\mathrm{NO}_{2}$ on the C-, N-, and O-doped borophene decreased. Except for the adsorption configuration of $\mathrm{CO}$ on $\mathrm{N}$-doped borophene (the most stable adsorption site was the T-site), the most stable adsorption site of the other adsorption configurations was the VB-site (the center of the valley bottom B-B bond). In addition, the adsorption energies of the most stable adsorption configurations are shown in Figure 3(d), where the adsorption energies of $\mathrm{CO}$ on $\mathrm{C}-, \mathrm{N}$-, and $\mathrm{O}$-doped borophene were $-1.45,-1.70$, and $-1.86 \mathrm{eV}$, respectively, and these values were larger than those for the adsorption of $\mathrm{CO}$ on pristine borophene $(-0.761 \mathrm{eV})$ [14] and the adsorption of $\mathrm{CO}$ on graphene $(-0.12 \mathrm{eV})$. Besides, we also systematically analyzed the variations of bond length and bond angle before and after gas small molecule adsorption, as shown in Table 2. The bond length of $\mathrm{C}-\mathrm{O}$ is $1.220 \AA$, $1.191 \AA$, and $1.206 \AA$ after CO molecule adsorbed on the C-, $\mathrm{N}$-, and $\mathrm{O}$-doped borophene, respectively. Compared with the free CO molecule (bond length of $1.154 \AA$ ), its bond length increases slightly after adsorption. These results showed that $\mathrm{CO}$ was chemisorbed on the $\mathrm{C}-, \mathrm{N}-$, and $\mathrm{O}$-doped borophene in a perpendicular direction to the borophene sheet, and the adsorption structure is shown in Figure 4. In addition, similar adsorption structures were observed, with six-membered vacancy rings of the doped borophene and $\mathrm{CO}$ molecule adsorbing vertically on the borophene (Figure 4 (a1)-(a6)). The adsorption energies of $\mathrm{CO}_{2}$ on $\mathrm{C}$-, $\mathrm{N}$-, and $\mathrm{O}$-doped borophene were $-0.64,-1.34$, and $-0.71 \mathrm{eV}$, respectively. Compared with the adsorption energy of $\mathrm{CO}_{2}$ on pristine borophene $(-0.898 \mathrm{eV})$, the carbon atom and oxygen atom doping resulted in a decrease in the adsorption energy of borophene for $\mathrm{CO}_{2}$, while nitrogen atom doping led to an increase in adsorption energy. As shown in Figure 4 (b1)-(b6), we found that $\mathrm{CO}_{2}$ chemisorbed on C-, N-, and O-doped borophene. After adsorption, the borophene structure was disrupted, the bond length $\mathrm{C}-\mathrm{O}$ increased obviously (the length of $\mathrm{C}_{2}-\mathrm{O}_{2}$ bond extends to $1.409 \AA, 1.343 \AA$, and $1.362 \AA$ from $1.161 \AA$ (free $\mathrm{CO}_{2}$ molecule) for the $\mathrm{CO}_{2}$-C-doped, $\mathrm{CO}_{2}-\mathrm{N}$-doped, and $\mathrm{CO}_{2}$-O-doped borophene adsorption configurations, respectively), and the bond angle of the $\mathrm{CO}_{2}$ molecule changed from $180^{\circ}$ to $117.655^{\circ}$ (C-doped borophene), $112.827^{\circ}(\mathrm{N}$ doped borophene), and $114.176^{\circ}$, (O-doped borophene). The 


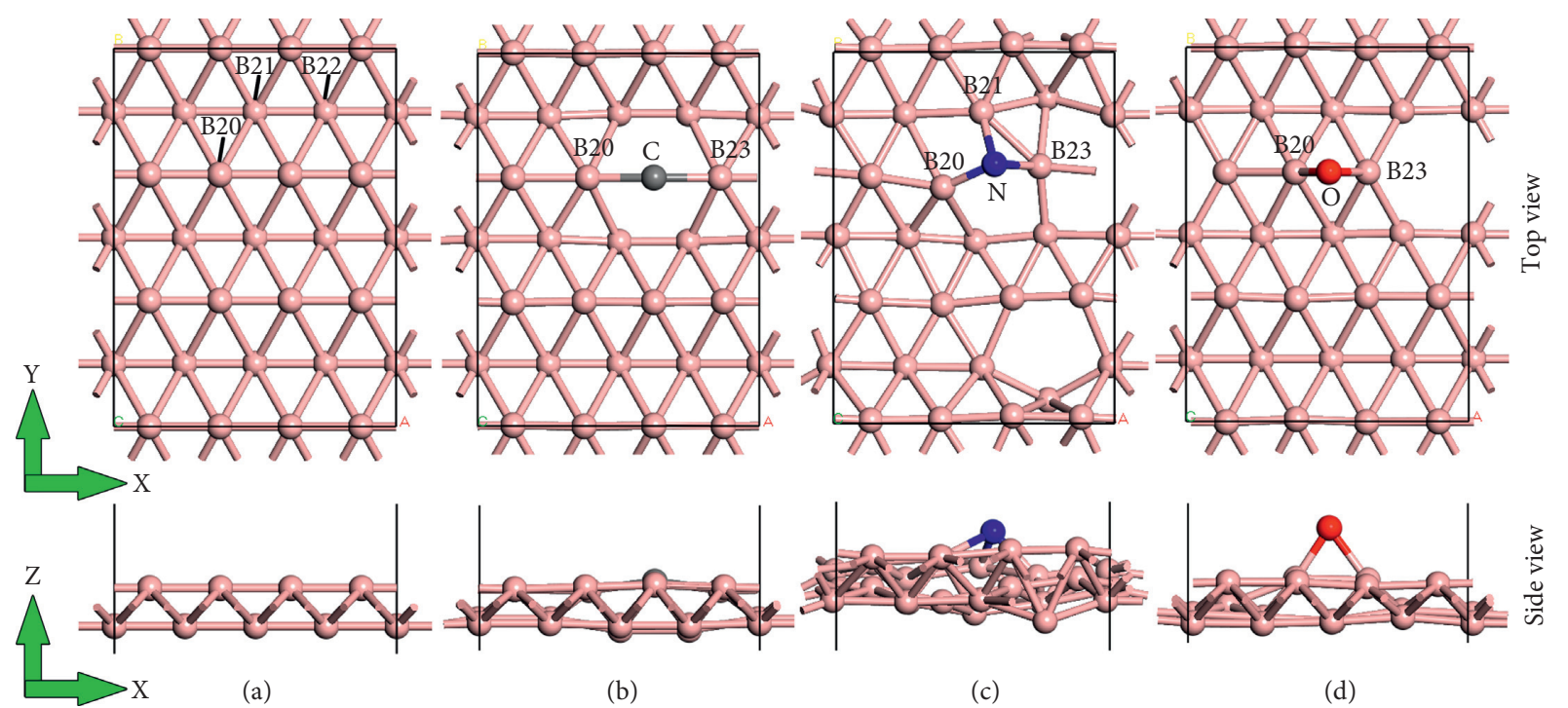

Figure 2: The top and side views of the fully relaxed structure for (a) pristine, (b) C-doped, (c) N-doped, and (d) O-doped borophene.

TABLE 1: The relevant bond length, bond population, and atomic population for the pristine borophene, C-doped, N-doped, and O-doped borophene, respectively.

\begin{tabular}{|c|c|c|c|c|c|}
\hline & Bond & Length $(\AA)$ & Bond populations & Atom & Atomic charge populations (e) \\
\hline \multirow{3}{*}{ Pristine borophene } & \multirow{3}{*}{$\begin{array}{l}\text { B20-B21 } \\
\text { B21-B22 }\end{array}$} & \multirow{3}{*}{$\begin{array}{l}1.880 \\
1.626\end{array}$} & \multirow{3}{*}{$\begin{array}{l}0.20 \\
0.20\end{array}$} & $\mathrm{~B} 20$ & 0.0 \\
\hline & & & & B21 & 0.0 \\
\hline & & & & $\mathrm{B} 22$ & 0.0 \\
\hline \multirow{3}{*}{ C-doped borophene } & \multirow{3}{*}{$\begin{array}{l}\text { B20-C } \\
\text { B23-C }\end{array}$} & \multirow{3}{*}{$\begin{array}{l}1.541 \\
1.538\end{array}$} & \multirow{3}{*}{$\begin{array}{l}1.16 \\
1.16\end{array}$} & $\mathrm{C}$ & -0.30 \\
\hline & & & & B20 & 0.13 \\
\hline & & & & $\mathrm{B} 23$ & 0.13 \\
\hline \multirow{4}{*}{$\mathrm{N}$-doped borophene } & \multirow{4}{*}{$\begin{array}{l}\text { B20-N } \\
\text { B21-N } \\
\text { B23-N }\end{array}$} & \multirow{4}{*}{$\begin{array}{l}1.449 \\
1.500 \\
1.500\end{array}$} & \multirow{4}{*}{$\begin{array}{l}0.91 \\
0.58 \\
0.76\end{array}$} & $\mathrm{~N}$ & -0.60 \\
\hline & & & & $\mathrm{B} 20$ & 0.38 \\
\hline & & & & B21 & 0.20 \\
\hline & & & & $\mathrm{B} 23$ & 0.35 \\
\hline \multirow{3}{*}{ O-doped borophene } & \multirow{3}{*}{$\begin{array}{l}\text { B20-O } \\
\text { B23-O }\end{array}$} & \multirow{3}{*}{$\begin{array}{l}1.412 \\
1.507\end{array}$} & \multirow{3}{*}{$\begin{array}{l}0.71 \\
0.53\end{array}$} & $\mathrm{O}$ & -0.62 \\
\hline & & & & B20 & 0.45 \\
\hline & & & & B23 & 0.34 \\
\hline
\end{tabular}

adsorption energies of $\mathrm{NO}$ on $\mathrm{C}-, \mathrm{N}$-, and $\mathrm{O}$-doped borophene were $-2.13,-1.81$, and $-2.86 \mathrm{eV}$, respectively, which were all smaller than the adsorption energy of $\mathrm{NO}$ on pristine borophene $(-4.043 \mathrm{eV})$. Furthermore, the adsorption structure was similar for the $\mathrm{CO}$ on the $\mathrm{C}-, \mathrm{N}$-, and O-doped borophene (Figure 4 (c1)-(c6)). Before adsorption, the bond length of $\mathrm{NO}$ molecule is $1.151 \AA$, and then it changed to around $1.265 \AA$ when adsorbed on doped borophene. Thus, C-, N-, and O-doped borophene notably increased the adsorption energy of $\mathrm{NO}_{2}$ on the doped borophene sheet (from $-2.836 \mathrm{eV}$ for pristine borophene to -5.30 , -3.82 , and $-3.92 \mathrm{eV}$ for $\mathrm{C}-, \mathrm{N}$-, and O-doped borophene, respectively). While the adsorption mechanism of the $\mathrm{NO}_{2}$ molecule on doped borophene differed from that of the $\mathrm{CO}, \mathrm{CO}_{2}$, and $\mathrm{NO}_{2}$ molecules, as shown in Figure 4 (d1)-(d6), the $\mathrm{NO}_{2}$ molecule dissociated into $\mathrm{N}$ and $\mathrm{NO}$, which then adsorbed on the $\mathrm{B}$ atoms and formed O2-N2 bond (bond length of $1.247 \AA$, $1.262 \AA$, and $1.264 \AA$ for $\mathrm{C}$-, $\mathrm{N}$-, and O-doped borophene, respectively) and O3B1 bond (bond length of 1.221 $\AA, 1.219 \AA$, and 1.223 $\AA$ for C-, N-, and $\mathrm{O}$-doped borophene, respectively). This indicated that $\mathrm{NO}_{2}$ adsorption on $\mathrm{C}$-, $\mathrm{N}$-, and $\mathrm{O}$-doped borophene was more stable.
The calculated adsorption energies and configurations of the small gas molecules and doped borophene revealed that $\mathrm{CO}_{2}$ chemisorbed on $\mathrm{C}$ - and $\mathrm{O}$-doped borophene with a more moderate adsorption energy value compared to pristine borophene. Thus, the $\mathrm{C}$ and $\mathrm{O}$ atom-doped borophene materials would be more suitable as $\mathrm{CO}_{2}$ molecule sensors. Although the $\mathrm{C}, \mathrm{N}$, and $\mathrm{O}$ atom-doped borophene could partly reduce the adsorption energy of the borophene sheet for NO, the adsorption energy was still approximately $-2.0 \mathrm{eV}$. Additionally, the adsorption energies of $\mathrm{CO}$ and $\mathrm{NO}_{2}$ molecules on $\mathrm{C}$-, $\mathrm{N}$-, and $\mathrm{O}$-doped borophene increased. Therefore, $\mathrm{CO}, \mathrm{NO}$, and $\mathrm{NO}_{2}$ chemisorbed on $\mathrm{C}-$, $\mathrm{N}$-, and $\mathrm{O}$-doped borophene with stronger adsorption energies, and desorption did not easily occur.

3.3. Work Functions for Different Gas-Doped Borophene Adsorption Configurations. According to the different detecting principles, gas molecule sensors can be divided into chemical resistors, field effect transistors, and surface 


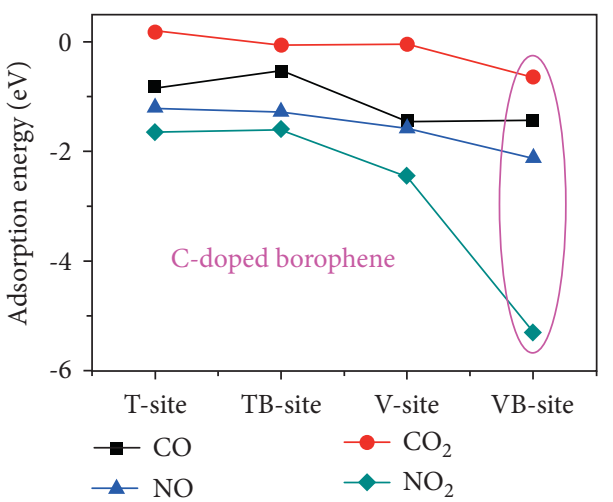

(a)

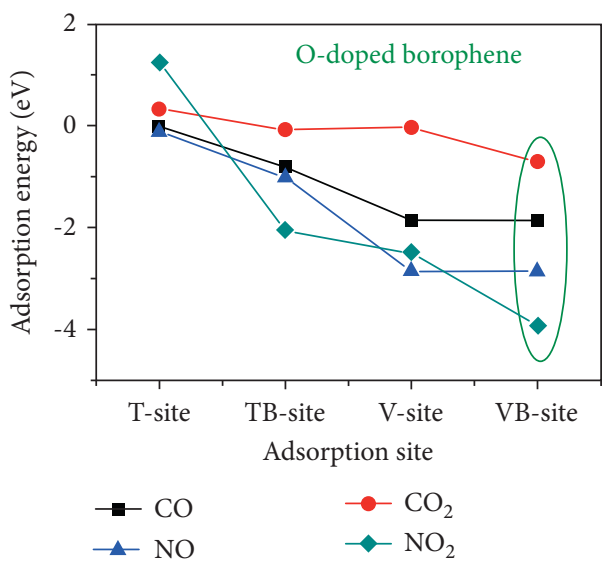

(c)

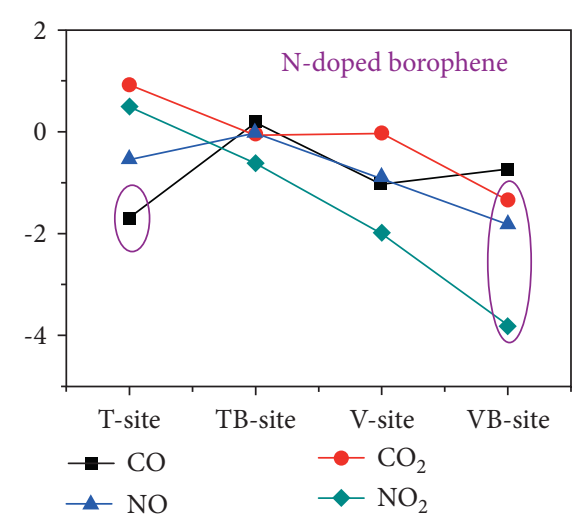

(b)

\begin{tabular}{lccc}
\hline & \multicolumn{3}{c}{ Adsorption energy (eV) } \\
\hline & C-do & N-do & O-do \\
\hline $\mathrm{CO}$ & -1.45 & -1.70 & -1.86 \\
\hline $\mathrm{CO}_{2}$ & -0.64 & -1.34 & -0.71 \\
\hline $\mathrm{NO}$ & -2.13 & -1.81 & -2.86 \\
\hline $\mathrm{NO}_{2}$ & -5.30 & -3.82 & -3.93 \\
\hline
\end{tabular}

(d)

Figure 3: The adsorption energy curves of the gas molecules on $\mathrm{C}-, \mathrm{N}-$, and $\mathrm{O}$-doped borophene.

work functions transistors [31]. The chemical resistors are one of the most popular gas sensors, whose working mechanism is to detect the changes in electrical conductance (band gap value) caused by adsorption of small gas molecules. However, we found that the band gap of heteroatom-doped (C-, N-, and $\mathrm{O}-$ ) borophene is $0 \mathrm{eV}$ before and after gas small molecules adsorption based on the DFT calculations. This phenomenon limits the application of heteroatom-doped borophene as a chemical resistor to detecting gas small molecules. Other widely studied sensing devices are surface work function changed transistors which depend on the work function change caused by the gas small molecules adsorption. Work function is defined as the minimum energy required to move an electron from the Fermi level to the vacuum level. The variation of surface work function is a measurable quantity after gas small molecules adsorption on the adsorbent. Therefore, through analysis, the change of surface work function caused by the gas molecules adsorption, the heteroatom-doped borophene can be used as a surface work function transistor to detecting gas small molecules. Figure 5 shows the changes of surface work function caused by the heteroatom-doped borophene and gas small molecules adsorption. The work function of pristine borophene is $5.157 \mathrm{eV}$, which is consistent with the $5.310 \mathrm{eV}$ from Kistanov's calculations [32]. After the carbon, nitrogen, and oxygen atom doping the borophene, the work function of C-doped,
$\mathrm{N}$-doped, and O-doped borophene is $4.928 \mathrm{eV}, 4.735 \mathrm{eV}$, and $5.26 \mathrm{eV}$, respectively. Due to the charge transfer between the borophene and heteroatom $(\mathrm{C}, \mathrm{N}$, and $\mathrm{O})$, the carbon and nitrogen atom doping leads to the work function decreases, but the oxygen doping results in the work function increases. From Figure 5(b) and the red column inset, the $\mathrm{CO}_{2}, \mathrm{NO}$, and $\mathrm{NO}_{2}$ molecules adsorbed on the C-doped borophene result in the work function increases of $0.043 \mathrm{eV}, 0.083 \mathrm{eV}$, and $0.473 \mathrm{eV}$, respectively, but the $\mathrm{CO}$ molecule adsorbed on the C-doped borophene leads to the work function decrease of $0.235 \mathrm{eV}$. The variation of work function of heteroatomdoped borophene larger than $0.40 \mathrm{eV}$ was caused by gas small molecules indicating that the heteroatom-doped borophenes are very sensitive to these gas small molecules [31]. The CO, $\mathrm{CO}_{2}, \mathrm{NO}$, and $\mathrm{NO}_{2}$ molecules adsorbed on the $\mathrm{N}$-doped borophene lead to the work function increases, and the increment is $0.548 \mathrm{eV}, 0.662 \mathrm{eV}, 0.165 \mathrm{eV}$, and $0.723 \mathrm{eV}$, respectively (Figure 5(c) and the blue column inset). For the condition of O-doped borophene, the $\mathrm{CO}$ and NO molecule adsorption only results in the slight increase of work function $\left(0.06 \mathrm{eV}\right.$ and $0.029 \mathrm{eV}$, respectively). The $\mathrm{CO}_{2}$ molecule adsorption results in a $0.41 \mathrm{eV}$ reduction, and the $\mathrm{NO}_{2}$ molecule adsorption leads to a significant increase of $1.228 \mathrm{eV}$ in the work function. Based on the above analysis, from the viewpoint of work function, we can conclude that the C-doped borophene based gas sensor only detected the $\mathrm{NO}_{2}$ molecule, 


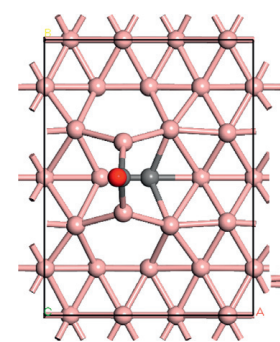

(a1)

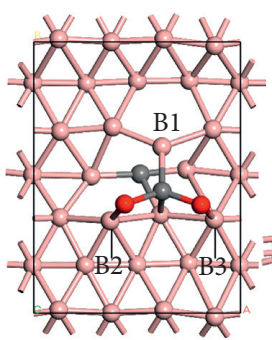

(b1)

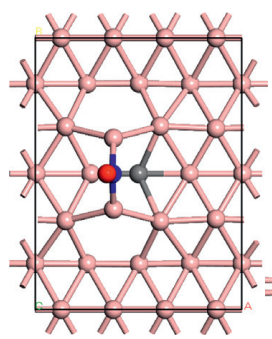

(c1)

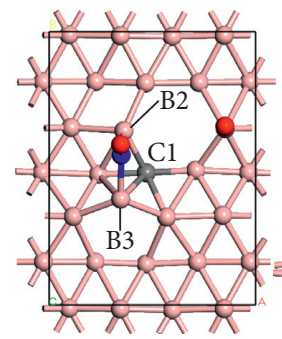

(d1)

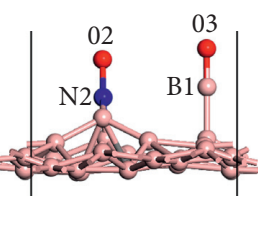

(d2)

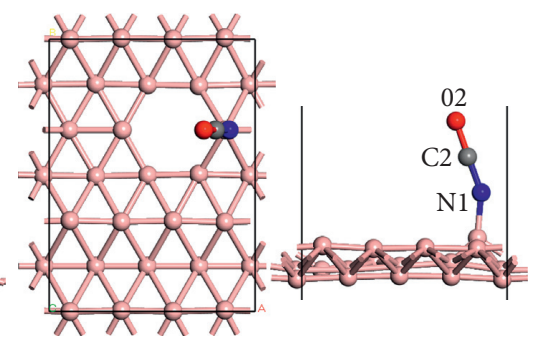

(a3)

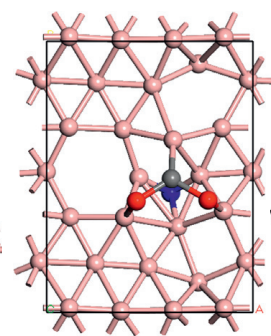

(b3)

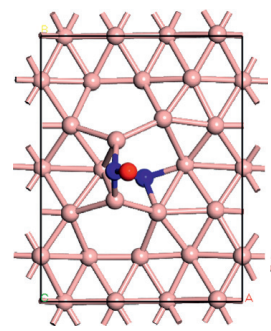

(c3)

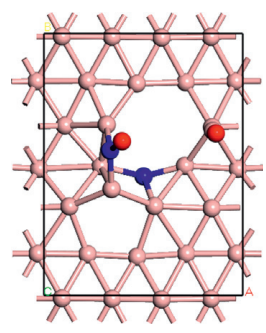

(d3)

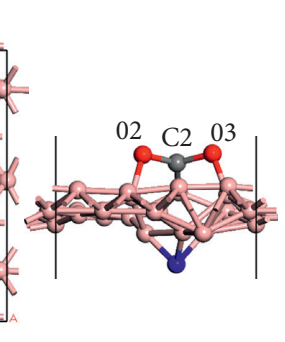

(b4)

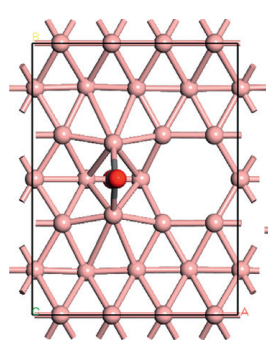

(a5)

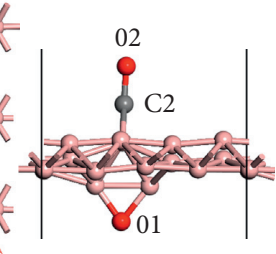

(a6)

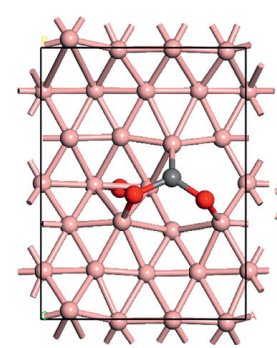

(b5)

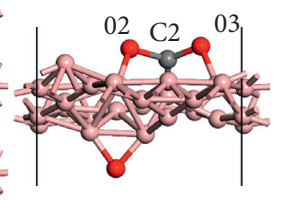

(b6)

Figure 4: Atomic structures of the most stable configurations for small gas molecule adsorption on C-, N-, and O-doped borophene: (a1-a6) $\mathrm{CO}$ molecule adsorbed on $\mathrm{C}-, \mathrm{N}$-, and $\mathrm{O}$-doped borophene, respectively; (b1-b6) $\mathrm{CO}_{2}$ molecule adsorbed on $\mathrm{C}$-, $\mathrm{N}$-, and $\mathrm{O}$-doped borophene, respectively; (c1-c6) NO molecule adsorbed on C-, N-, and O-doped borophene, respectively; (d1-d6) $\mathrm{NO}_{2}$ molecule adsorbed on C-, N-, and O-doped borophene, respectively.

TABLE 2: The variation of bond length and bond angle of gas molecule before and after adsorption.

\begin{tabular}{|c|c|c|c|c|c|}
\hline \multirow{3}{*}{ Gas molecule } & \multirow{3}{*}{ Bond } & \multicolumn{4}{|c|}{ Bond length $(\AA)$} \\
\hline & & \multirow{2}{*}{ Before adsorption } & \multicolumn{3}{|c|}{ After adsorption } \\
\hline & & & C-doped & $\mathrm{N}$-doped & O-doped \\
\hline $\mathrm{CO}$ & $\mathrm{C}_{2}-\mathrm{O}_{2}$ & 1.154 & 1.220 & 1.191 & 1.206 \\
\hline \multirow[b]{2}{*}{$\mathrm{CO}_{2}$} & $\mathrm{C}_{2}-\mathrm{O}_{2}$ & 1.161 & 1.409 & 1.434 & 1.362 \\
\hline & $\mathrm{C}_{2}-\mathrm{O}_{2}$ & 1.161 & 1.400 & 1.373 & 1.334 \\
\hline \multirow{2}{*}{ NO } & $\mathrm{N}_{2}-\mathrm{O}_{2}$ & 1.151 & 1.265 & 1.260 & 1.269 \\
\hline & $\mathrm{N}_{2}-\mathrm{O}_{2}$ & 1.197 & 1.247 & 1.262 & 1.264 \\
\hline \multirow{2}{*}{$\mathrm{NO}_{2}$} & $\mathrm{~N}_{2}-\mathrm{O}_{3}$ & 1.197 & - & - & - \\
\hline & $\mathrm{O}_{3}-\mathrm{B}_{1}$ & 一 & 1.221 & 1.219 & 1.223 \\
\hline \multicolumn{6}{|c|}{ Bond angle } \\
\hline $\mathrm{CO}_{2}$ & $\angle \mathrm{O}_{2}-\mathrm{C}_{2}-\mathrm{O}_{3}$ & $180^{\circ}$ & $117.655^{\circ}$ & $112.827^{\circ}$ & $114.176^{\circ}$ \\
\hline $\mathrm{NO}_{2}$ & $\angle \mathrm{O}_{2}-\mathrm{N}_{2}-\mathrm{O}_{3}$ & $142.357^{\circ}$ & 一 & 一 & - \\
\hline
\end{tabular}




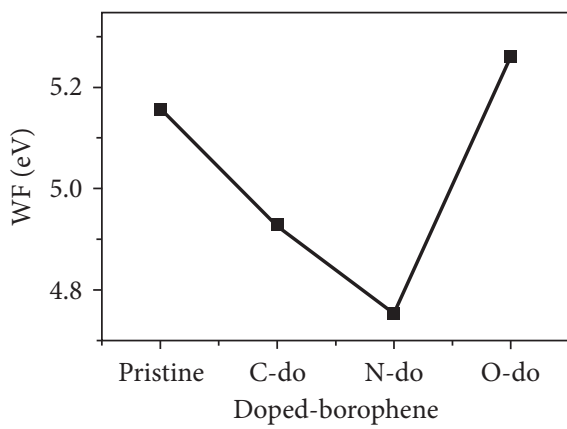

(a)

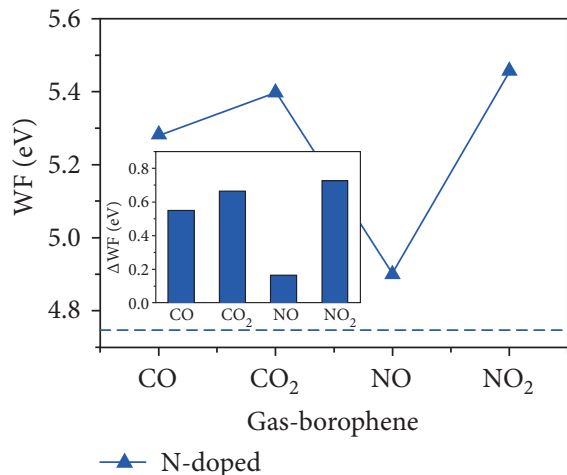

(c)

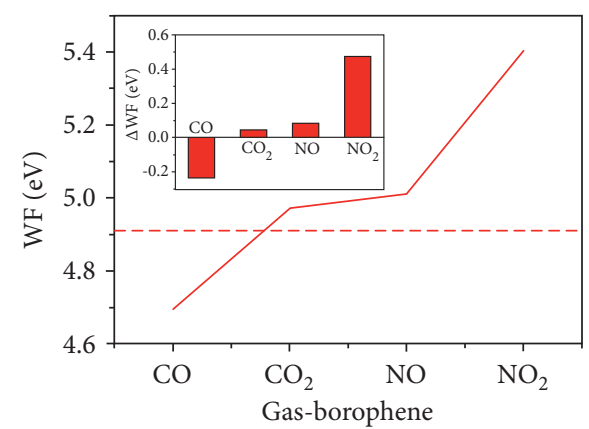

- C-doped

(b)

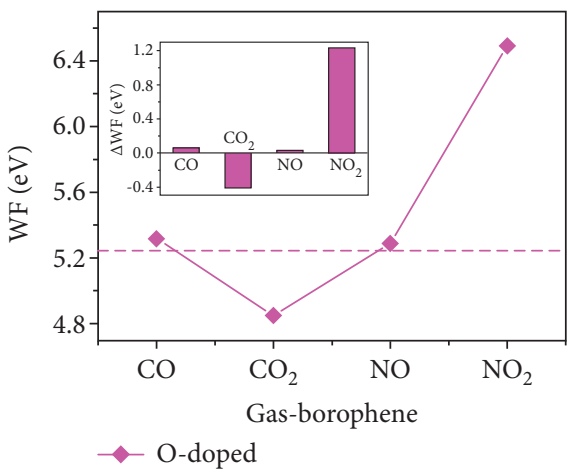

(d)

FIgURE 5: The work functions and their changes caused by the heteroatom-doped borophene and gas small molecules adsorption. (a) The C-, $\mathrm{N}$-, and O-doped borophene. (b), (c) and (d) The gas-C-doped borophene configurations, gas-N-doped borophene configurations, and O-doped borophene configurations, respectively. The red, blue, and magenta columns denote the variation of gas adsorption, respectively. The red, blue, and magenta dashed lines denote the work function of C-doped, N-doped, and O-doped borophene, respectively.

and the $\mathrm{N}$-doped borophene can be used as surface work function gas sensor to detect the $\mathrm{CO}, \mathrm{CO}_{2}$, and $\mathrm{NO}_{2}$ molecule, and $\mathrm{O}$-doped borophene based gas sensor can detect the $\mathrm{CO}_{2}$ and $\mathrm{NO}_{2}$ molecule.

3.4. Electronic Properties of C-Doped Borophene $/ \mathrm{CO}_{2}$ and $\mathrm{NO}_{2}$ Systems. Based on the Mulliken [33] populations algorithm, the population distribution of charges for the $\mathrm{C}$-doped borophene $/ \mathrm{CO}_{2}$ and $\mathrm{C}$-doped borophene/ $\mathrm{NO}_{2}$ systems before and after adsorption was calculated, and the results are presented in Table 3.

The population changes for the most stable C-doped borophene $/ \mathrm{CO}_{2}$ adsorption system are presented in the first section of Table 3, which shows that the $\mathrm{C} 2, \mathrm{O} 2$, and $\mathrm{O} 3$ atoms in $\mathrm{CO}_{2}$ gained $0.71,0.02$, and $0.01 \mathrm{e}$, respectively. In addition, the $\mathrm{B} 1, \mathrm{~B} 2$, and $\mathrm{B} 3$ atoms in $\mathrm{C}$-doped borophene in contact with the adsorbed $\mathrm{CO}_{2}$ molecule lost $0.09,0.55$, and $0.43 \mathrm{e}$, respectively ( $\mathrm{C} 1$ atom of $\mathrm{C}$-doped borophene gained $0.1 \mathrm{e})$. For the most stable adsorption configuration of the C-doped borophene/ $\mathrm{NO}_{2}$ system, the $\mathrm{N} 2, \mathrm{O} 2$, and $\mathrm{O} 3$ atoms in the $\mathrm{NO}_{2}$ molecule gained $0.51,0.01$, and $0.47 \mathrm{e}$, respectively. The B1, B2, and B3 atoms lost 0.61, 0.40, and 0.35 e, respectively. Therefore, we found significant differences in gained electrons for the $\mathrm{O} 2$ and $\mathrm{O} 3$ atoms, mainly because the $\mathrm{O} 3$ atom first separated from the $\mathrm{NO}_{2}$ molecule and then
TABLE 3: Calculated charge populations of the most stable C-doped borophene/ $\mathrm{CO}_{2}$ and $\mathrm{C}$-doped borophene/ $\mathrm{NO}_{2}$ systems.

Mulliken charge population

Atom Before adsorption After adsorption

(e)

(e)

\begin{tabular}{lccccccc} 
& & $\mathrm{s}$ & $\mathrm{p}$ & Charge & $\mathrm{s}$ & $\mathrm{p}$ & Charge \\
\hline & $\mathrm{C} 2$ & 0.68 & 2.34 & 0.98 & 1.15 & 2.59 & 0.27 \\
& $\mathrm{O} 2$ & 1.83 & 4.66 & -0.49 & 1.83 & 4.68 & -0.51 \\
C-doped & O3 & 1.83 & 4.66 & -0.49 & 1.82 & 4.68 & -0.50 \\
borophene $/ \mathrm{CO}_{2}$ & $\mathrm{C} 1$ & 1.30 & 3.00 & -0.30 & 1.30 & 3.10 & -0.40 \\
& $\mathrm{~B} 1$ & 0.83 & 2.08 & 0.09 & 0.87 & 1.94 & 0.18 \\
& $\mathrm{~B} 2$ & 0.77 & 2.24 & -0.02 & 0.64 & 1.83 & 0.53 \\
& $\mathrm{~B} 3$ & 0.83 & 2.08 & 0.09 & 0.64 & 1.83 & 0.52 \\
\hline & $\mathrm{N} 2$ & 1.38 & 3.19 & 0.43 & 1.47 & 3.61 & -0.08 \\
& O2 & 1.85 & 4.36 & -0.21 & 1.87 & 4.36 & -0.22 \\
C-doped & O3 & 1.85 & 4.36 & -0.21 & 1.86 & 4.81 & -0.68 \\
borophene $/ \mathrm{NO}_{2}$ & $\mathrm{C} 1$ & 1.30 & 3.00 & -0.30 & 1.25 & 3.21 & -0.47 \\
& $\mathrm{~B} 1$ & 0.83 & 2.08 & 0.09 & 0.70 & 1.60 & 0.70 \\
& $\mathrm{~B} 2$ & 0.73 & 2.32 & -0.06 & 0.73 & 1.93 & 0.34 \\
& B3 & 0.77 & 2.24 & -0.02 & 0.90 & 1.78 & 0.33 \\
\hline
\end{tabular}

bonded with the $\mathrm{B} 1$ atom in doped borophene (Figure 4 (d1) and (d2)). Thus, charge transfer occurred mainly in the $2 s$ and $2 \mathrm{p}$ orbitals of the atom. These results showed that both the $\mathrm{CO}_{2}$ and $\mathrm{NO}_{2}$ gas molecules acted as electron acceptors, and the C-doped borophene acted as an electron donor. 


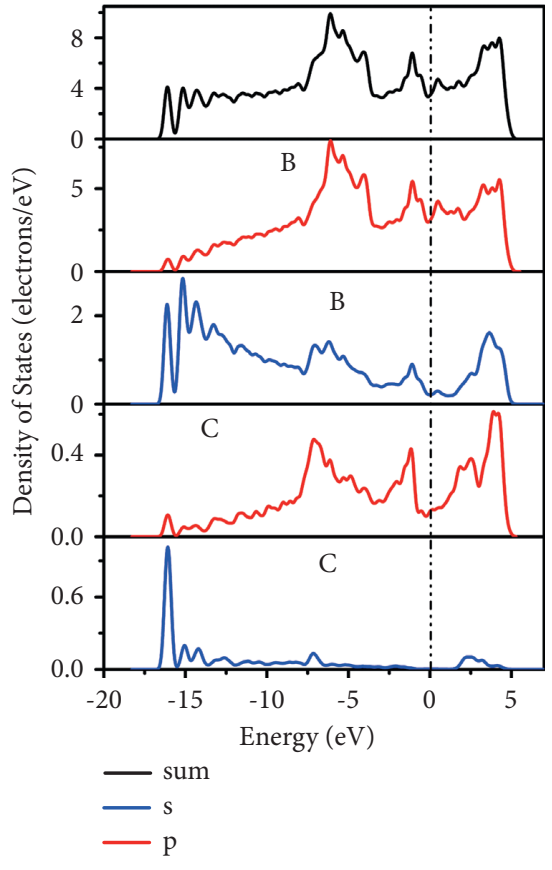

(a)

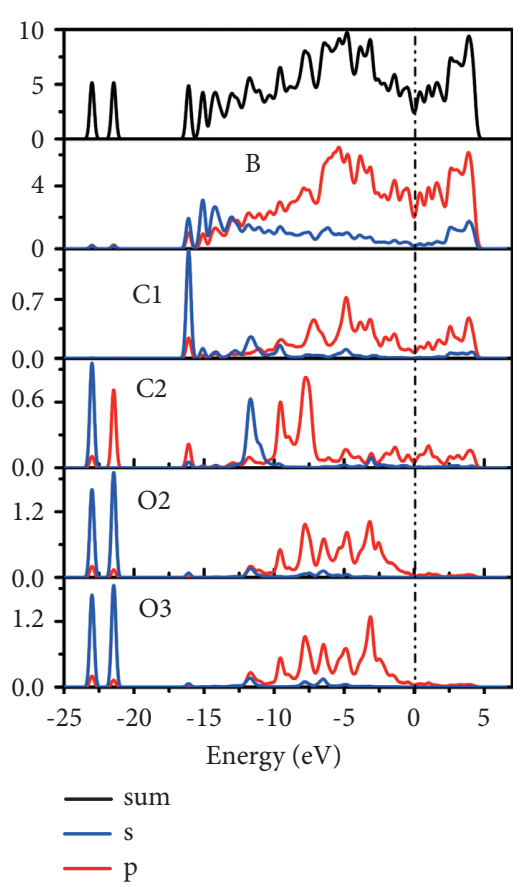

(b)

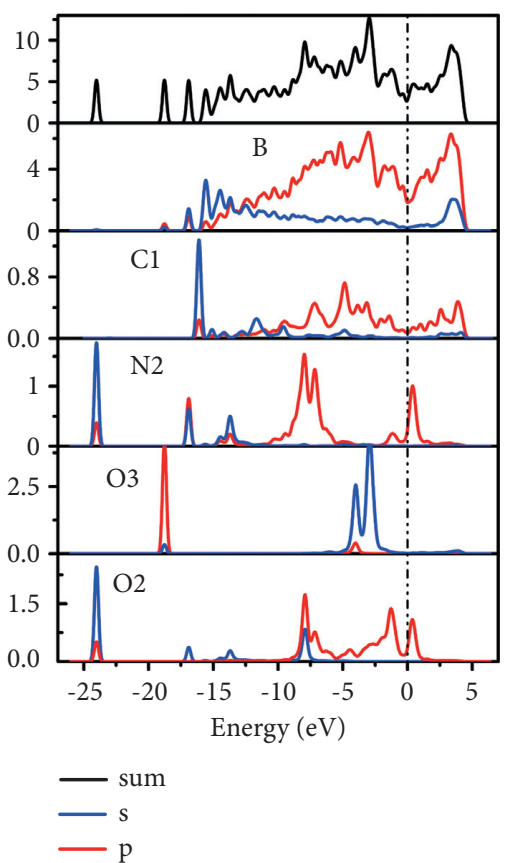

(c)

FIGURE 6: The density of states (DOS) calculations of the most stable adsorption structure: (a) PDOS of C-doped borophene before gas molecule adsorption; (b) TDOS and PDOS of the C-doped borophene/ $\mathrm{CO}_{2}$ system; and (c) TDOS and PDOS of the C-doped borophene/ $\mathrm{NO}_{2}$ system.

To further understand the interaction mechanisms between borophene and the gas molecules after adsorption, the changes in the DOS of the C-doped borophene and gas molecules before and after adsorption were analyzed. We calculated the DOS (including the total density of states (TDOS) and partial DOS (PDOS)) of the C-doped borophene, C-doped borophene/ $\mathrm{CO}_{2}$ adsorption, and C-doped borophene/ $\mathrm{NO}_{2}$ adsorption systems, as shown in Figure 6 .

Comparing Figures 6(a), 6(b), and 6(c) and the TDOS and PDOS before and after adsorption of the small gas molecule on C-doped borophene, we concluded that gas molecule adsorption on C-doped borophene caused charge transfer, which then broke and formed covalent bonds. When the $\mathrm{CO}_{2}$ molecule adsorbed on C-doped borophene, the DOS became deeper (from $-16.5 \sim 5 \mathrm{eV}$ to $-25 \sim 5 \mathrm{eV}$ ). This DOS range, from -25 to $-20 \mathrm{eV}$, was mainly due to the $2 s$ and $2 p$ orbitals of the $\mathrm{C} 2$ atom and the $2 s$ orbitals of the $\mathrm{O} 2, \mathrm{O} 3$ atoms (Figure $6(\mathrm{~b})$ ). In addition, the $2 \mathrm{~s}$ and $2 \mathrm{p}$ orbitals of the $\mathrm{B}, \mathrm{C} 1, \mathrm{C} 2, \mathrm{O} 2$, and $\mathrm{O} 3$ atoms overlapped, and the obvious resonance $\mathrm{C}$-doped borophene/ $\mathrm{CO}_{2}$ adsorption structure indicated covalent bonds between the $\mathrm{C} 2-\mathrm{B} 1, \mathrm{O} 2-$ B2, and B3-O3 atoms (Figure 4 (b1) and (b2)). The analysis results of the C-doped borophene/ $\mathrm{NO}_{2}$ configuration of DOS (Figure 6(c)) were similar to the results of the C-doped borophene/ $\mathrm{CO}_{2}$ system. After the $\mathrm{NO}_{2}$ molecule adsorbed on the C-doped borophene sheet, the DOS also became deeper, and the deeper DOS level was mainly due to the $2 \mathrm{~s}$ and $2 p$ orbitals of the $\mathrm{N} 2$ and $\mathrm{O} 2$ atoms. As shown in Figure 6(c), we also found obvious orbital hybridization of the $2 \mathrm{~s}$ orbitals in the $\mathrm{B}, \mathrm{N} 2$, and $\mathrm{O} 2$ atoms, from approximately -25 to $-22.5 \mathrm{eV}$, as shown by the interactions between the $\mathrm{B}, \mathrm{N} 2$, and $\mathrm{O} 2$ atoms. However, there was no obvious orbital hybridization between the $\mathrm{N} 2$ and $\mathrm{O} 3$ atoms from -25 to $5 \mathrm{eV}$, as the $\mathrm{O} 3$ atom had already separated from the $\mathrm{NO}_{2}$ molecule. Between -20 and $-17.5 \mathrm{eV}$, both the $2 \mathrm{~s}$ and $2 \mathrm{p}$ orbitals of the $\mathrm{B}$ and $\mathrm{O} 3$ atoms overlapped, indicating that B1-O3 formed covalent bonds (Figure 4 (d1) and (d2)). Therefore, the DOS analysis results were consistent with the atomic configuration analysis and Mulliken charge population results.

\section{Conclusions}

Using first-principles calculations based on DFT, we studied the adsorption behavior of $\mathrm{CO}, \mathrm{CO}_{2}, \mathrm{NO}$, and $\mathrm{NO}_{2}$ gas molecules on $\mathrm{C}-, \mathrm{N}-$, and $\mathrm{O}$-doped borophene sheets. By comparing the adsorption energies and adsorption configurations of the gas molecules on the four adsorption sites in borophene, we determined that most of the gas molecules formed relatively stable chemisorption bonds at the VB site (the center of the valley bottom B-B bond) on C-, N-, and $\mathrm{O}$-doped borophene (only the $\mathrm{CO}$ molecule adsorbed on the $\mathrm{T}$-site in $\mathrm{N}$-doped borophene). Compared to pristine borophene, $\mathrm{C}, \mathrm{N}$, and $\mathrm{O}$ atom doping increased the adsorption energies of the gas small molecules on borophene, making the adsorption configuration more stable. Furthermore, by analyzing the variations in DOS before and after adsorption, the effects of gas molecules on the electronic states of the C-, $\mathrm{N}$-, and $\mathrm{O}$-doped borophene were investigated to provide a microscopic understanding of the interactions between the 
gas molecules and the borophene sheet. In contrast to variations in the adsorption energies, electronic properties, and surface work functions of the different gas, C-, N-, and $\mathrm{O}$-doped borophene adsorption systems, we concluded that the $\mathrm{C}-, \mathrm{N}$-, and $\mathrm{O}$-doped borophene materials will improve the sensitivity of $\mathrm{CO}, \mathrm{CO}_{2}$, and $\mathrm{NO}_{2}$ molecule. This improvement of adsorption properties indicated that $\mathrm{C}-, \mathrm{N}-$, and $\mathrm{O}$-doped borophene materials are excellent candidates for surface work functions transistor to detect gas molecules.

\section{Data Availability}

The data used to support the findings of this study are included within the article.

\section{Conflicts of Interest}

The authors declare that they have no conflicts of interest.

\section{Acknowledgments}

This work was supported by the Youth Growth Project of the Education Department of Guizhou Province (No. 2017279), the Key Laboratory of Materials Simulation and Computing of Anshun University (Asxyxkpt201803), and the Youth Science and Technology Talent Growth Project of the Education Department of Guizhou Province (No. 2020138).

\section{References}

[1] K. S. Novoselov, A. K. Geim, S. V. Morozov et al., "Electric field effect in atomically thin carbon films," Science, vol. 306, no. 5696, pp. 666-669, 2004.

[2] A. J. Mannix, X. F. Zhou, B. Kiraly et al., "Synthesis of borophenes: anisotropic, two-dimensional boron polymorphs," Science, vol. 350, no. 6267, pp. 1513-1516, 2015.

[3] D. Li, J. He, G. Ding et al., "Stretch-driven increase in ultrahigh thermal conductance of hydrogenated borophene and dimensionality crossover in phonon transmission," Advanced Functional Materials, vol. 28, no. 31, Article ID 1801685, 2018.

[4] H. Sun, Q. Li, and X. G. Wan, "First-principles study of thermal properties of borophene," Physical Chemistry Chemical Physics, vol. 18, no. 22, pp. 14927-14932, 2016.

[5] Z. Wang, T. Y. Lü, H. Q. Wang, Y. P. Feng, and J. C. Zheng, "New crystal structure prediction of fully hydrogenated borophene by first principles calculations," Scientific Reports, vol. 7, no. 1, p. 609, 2017.

[6] B. Peng, H. Zhang, H. Shao, Y. Xu, R. Zhang, and H. Zhu, "The electronic, optical, and thermodynamic properties of borophene from first-principles calculations," Journal of Materials Chemistry C, vol. 4, no. 16, pp. 3592-3598, 2016.

[7] J. H. Liao, Y. C. Zhao, Y. J. Zhao, H. Xu, and X. B. Yang, "Phonon-mediated superconductivity in $\mathrm{Mg}$ intercalated bilayer borophenes," Physical Chemistry Chemical Physics, vol. 19, no. 43, pp. 29237-29243, 2017.

[8] Z. Zhang, Y. Yang, E. S. Penev, and B. I. Yakobson, "Elasticity, flexibility and ideal strength of borophenes," Advanced Functional Materials, vol. 27, no. 9, Article ID 1605059, 2017.

[9] X. Zhang, J. Hu, Y. Cheng, H. Y. Yang, Y. Yao, and S. A. Yang, "Borophene as an extremely high capacity electrode material for Li-ion and Na-ion batteries," Nanoscale, vol. 8, no. 33, pp. 15340-15347, 2016.
[10] J. Liu, C. Zhang, L. Xu, and S. Ju, "Borophene as a promising anode material for sodium-ion batteries with high capacity and high rate capability during DFT," RSC Advances, vol. 8, no. 32, pp. 17773-17785, 2018.

[11] S. Er, G. A. de Wijs, and G. Brocks, "DFT study of planar boron sheets: a new template for hydrogen storage," The Journal of Physical Chemistry C, vol. 113, no. 43, pp. 1896218967, 2009.

[12] L. Li, H. Zhang, and X. Cheng, "The high hydrogen storage capacities of Li-decorated borophene," Computational Materials Science, vol. 137, pp. 119-124, 2017.

[13] H. Li, L. Jing, W. Liu et al., "Scalable production of few-layer boron sheets by liquid-phase exfoliation and their superior supercapacitive performance," ACS Nano, vol. 12, no. 2, pp. 1262-1272, 2018.

[14] T. Liu, Y. Chen, M. Zhang et al., "A first-principles study of gas molecule adsorption on borophene," AIP Advances, vol. 7, no. 12, Article ID 125007, 2017.

[15] V. Nagarajan and R. Chandiramouli, "Borophene nanosheet molecular device for detection of ethanol - a first-principles study," Computational and Theoretical Chemistry, vol. 1105, pp. 52-60, 2017.

[16] H. Cui, X. Zhang, and D. Chen, "Borophene: a promising adsorbent material with strong ability and capacity for $\mathrm{SO} 2$ adsorption," Applied physics A, vol. 124, no. 9, p. 636, 2018.

[17] X. Tan, H. A. Tahini, and S. C. Smith, "Borophene as a promising material for charge-modulated switchable $\mathrm{CO}_{2}$ capture," ACS Applied Materials \& Interfaces, vol. 9, no. 23, pp. 19825-19830, 2017.

[18] R. Chandiramouli and V. nagarajan, "Borophene nanostructure as CO and NO sensor-a first-principles study," Vacuum, vol. 142, pp. 13-20, 2017.

[19] J. L. Shen, Z. Yang, Y. T. Wang, L.-C. Xu, R. Liu, and X. Liu, "The gas sensing performance of borophene/ $\mathrm{MoS}_{2}$ heterostructure," Applied Surface Science, vol. 504, Article ID 14412, 2020.

[20] J. Zeng and K. Q. Chen, "Charge transport in borophene: role of intrinsic line defects," The Journal of Physical Chemistry C, vol. 123, no. 10, pp. 6270-6275, 2019.

[21] S. Chowdhury, A. Majumdar, and D. Jana, "Electronic and optical properties of the supercell of 8-Pmmn borophene modified on doping by $\mathrm{H}, \mathrm{Li}, \mathrm{Be}$, and C: a DFT approach," Applied Physics A, vol. 125, no. 5, p. 360, 2019.

[22] X. Chen, L. Wang, W. Zhang, J. Zhang, and Y. Yuan, "Cadecorated borophene as potential candidates for hydrogen storage: a first-principle study," International Journal of Hydrogen Energy, vol. 42, no. 31, pp. 20036-20045, 2017.

[23] L. Wang, X. Chen, H. Du, Y. Yuan, H. Qu, and M. Zou, "Firstprinciples investigation on hydrogen storage performance of $\mathrm{Li}, \mathrm{Na}$ and K decorated borophene," Applied Surface Science, vol. 427, pp. 1030-1037, 2018.

[24] S. Kumar, M. Singh, D. K. Sharma, and S. Auluck, "Enhancing gas adsorption properties of borophene by embedding transition metals," Computational Condensed Matter, vol. 22, Article ID e00436, 2020.

[25] V. Arefi, A. Horri, and M. B. Yavakoli, "Transport properties of Na-decorated borophene under $\mathrm{CO} / \mathrm{CO}_{2}$ adsorption," Computational and Theoretical Chemistry, vol. 1197, Article ID 1131159, 2021.

[26] S. J. Clark, M. D. Segall, C. J. Pickard et al., "First principles methods using CASTEP," Zeitschrift für KristallographieCrystalline Materials, vol. 220, no. 5-6, pp. 567-570, 2005. 
[27] J. P. Perdew, K. Burke, and M. Ernzerhof, "Generalized gradient approximation made simple," Physical Review Letters, vol. 77, no. 18, pp. 3865-3868, 1996.

[28] D. Vanderbilt, "Soft self-consistent pseudopotentials in a generalized eigenvalue formalism," Physical Review B, vol. 41, no. 11, pp. 7892-7895, 1990.

[29] R. Gholizadeh and Y. X. Yu, "N2O + CO reaction over Si- and Se-doped graphenes: an ab initio DFT study," Applied Surface Science, vol. 357, pp. 1187-1195, 2015.

[30] R. Gholizadeh and Y. X. Yu, "Work functions of pristine and heteroatom-doped graphenes under different external electric fields: an ab initio DFT study," The Journal of Physical Chemistry C, vol. 118, no. 48, pp. 28274-28282, 2014.

[31] J. H. Li, J. Wu, and Y. X. Yu, "DFT explorations of sensor performances of two-dimensional $\mathrm{WO}_{3}$ to ten small gases in terms of work function and band gap changes and I-V responses," Applied Surface Science, vol. 546, Article ID 149104, 2021.

[32] A. A. Kistanov, Y. Cai, K. Zhou, N. Srikanth, S. V. Dmitriev, and Y.-W. Zhang, "Exploring the charge localization and band gap opening of borophene: a first-principles study," Nanoscale, vol. 10, no. 3, pp. 1403-1410, 2018.

[33] R. S. Mulliken, "Electron population analysis on LCAO-MO molecular wave functions," The Journal of Chemical Physics, vol. 23, no. 10, pp. 1833-1840, 1955. 